RUNNING HEAD: Facilitated Difficult Dialogues

\title{
Facilitated Difficult Dialogues on Racism: A Goal-Based Approach
}

\author{
Srividya Ramasubramanian \\ Texas A\&M University \\ Alexandra N. Sousa \\ Texas A\&M University \\ Vanessa Gonlin \\ Texas A\&M University
}

Suggested Citation: Ramasubramanian, S., Sousa, A. \& Gonlin, V. (2017). Facilitated dialogues to combat racism: A goal-based approach. Journal of Applied Communication Research, 45 (5), 537-556, doi:10.1080/00909882.2017.1382706. 
Authors' note: All correspondence relating to this paper should be addressed to Dr. Srividya Ramasubramanian, 202D Bolton Hall, Department of Communication, Mailstop 4234, Texas A\&M University, College Station, TX 77843-4234; srivi@tamu.edu. The authors would like to thank Dr. Mary Campbell and the TAMU Anti-Racism for generously sharing the vignettes that were used in the difficult dialogues. They are grateful to Aggie Agora, the expert facilitators, the difficult dialogue session participants for their support and inputs in shaping this dialogue series. They also sincerely thank Madeline Culver, Josh Harms, and Karen Banks for their assistance.

Author bios: Srividya Ramasubramanian is Associate Dean for Climate \& Inclusion in the College of Liberal Arts and Associate Professor in the Department of Communication at Texas A\&M University. Her interests are in cultural diversity, intergroup relations, and media stereotyping processes. Alexandra N. Sousa is a doctoral student in the Department of Communication at Texas A\&M University. Her research in organizational communication centers around issues of inclusion within higher education. Sousa is also a recent recipient of the Blackard 63' Fellowship in Communication. Vanessa Gonlin is a doctoral student and Diversity Fellow in the Department of Sociology at Texas A\&M University. Gonlin's research interests include studying patterns regarding multiracial identity, interracial relationships, and skin tone. 


\begin{abstract}
Racist incidents are moments that highlight the systemic racism that still exists within higher education. In 2016, the College of Liberal Arts at a historically White, Southern institution in the U.S. responded to a racist incident on campus by setting up a series of "Difficult Dialogue on Campus Race Relations" sessions that gave participants the opportunity to reflect and respond to the incident. Drawing on literature about racial dialogues and social identity theory, the sessions were designed to promote active listening, build empathy, and provide practical tools to combat everyday racial microaggressions. We describe how communication design elements (such as small group settings, localized case studies, role-play, and ground rules) were tailored to fit the needs of various group settings and analyze participants' feedback about the perceived impact of these dialogues. We present a goal-based dialogue framework as a model to facilitate difficult dialogues in a variety of applied communication contexts.
\end{abstract}

Keywords: dialogue, race and racism, diversity, social identity, communication design 
"This is the first time I think I've ever felt like I've had a productive discussion like this, even though I've been to several things claiming to be like this."

In February 2016, a group of minority high school students from a charter school came for a recruiting visit to a large historically White, Southern university. During their tour, they were confronted by White university students who yelled "Go back where you came from," along with other anti-Black racial slurs, in response to seeing the logo of a rival university on one student's shirt. Another White, female student approached the group and asked what they thought of her Confederate flag earrings (Hassan, Almasy, \& Valencia, 2016). The university's tour guides who observed this interaction notified campus police. Although an officer who responded to the scene first claimed that "it appeared to be a case of people exercising First Amendment rights," he later reported the incident (Hassan et. al, 2016).

Within a week, students involved in the incident were identified and the university president, as well as the student body president, released statements condemning the racist acts and the university's intolerance for racism. In an e-mail, the president outlined his response, which included introducing mandatory "Community of Respect" seminars during new student conferences and creating permanent funding for a diversity peer education program (Elbushra, 2016).

Although university officials directly addressed the incident, deep racial tensions within the school were revealed and the university community called for more long-term action to address ongoing discrimination on campus. Responding to the racist incident and related student protests, The College of Liberal Arts at the university set up a series of difficult dialogues on campus race relations in order for students to have productive conversations about the incident and develop ways to improve campus climate. Difficult dialogues here refer to how race 
complicates the communication process, in regards to both design and execution of such conversations. The results of these sessions inspired the current empirical study, which offers a complex case-study of how race and difference are perceived to influence dialogue, especially when dialogue is offered in response to racist incidents. Because participants approach these dialogues from different racial and cultural contexts, the communicative design of these dialogues should take the racial/ethnic identity of participants into consideration.

\section{Campus Racism and Everyday Racial Microaggressions}

Higher education institutions have long been sites of racism and systemic violence.

Universities "have not invested in the resources necessary to address the complexities of racial and ethnic diversity on predominantly White campuses" (Hamer \& Lang, 2015 p.905). Smith and colleagues (2016) also note that they prefer the phrase "historically White," as opposed to "predominantly White" to describe the university setting, in order to indicate that actual demographics of college campuses "have less to do with constituting the majority population than with the historical and contemporary racialized infrastructure that is in place" (p. 1190). Experiencing racism on campus can cause negative health outcomes, which can in turn affect the educational and personal wellbeing of marginalized students (Franklin, Smith, \& Hung, 2014). Racism that occurs on college campuses can be overt, but can also take the more concealed form of microaggressions (Minikel-Lacocque, 2013; Nadal, Wong, Griffin, Davidoff, \& Sriken, 2014). Overt racism is not typically "socially condoned," which make covert racist acts more relevant on college campuses (Minikel-Lacocque, 2013). Therefore, learning about and addressing microaggressions becomes an important task for diversity leaders on campuses.

Nadal (2011) defines racial microaggressions as "subtle statements and behaviors that unconsciously communicate denigrating messages to people of color" (p. 470). Microaggressions 
take three forms: (1) microinsults ("subtle snubs" that attack or disregard someone's identity), (2) microassaults (explicit attack, most closely tied to overt racism), and (3) microinvalidations (“negating or nullifying" someone's lived experience) (Sue et al., 2007, p. 274). Sue (2010) adds, microaggressions are "everyday verbal, nonverbal, and environmental slights, snubs, or insults, whether intentional or unintentional, that communicate hostile, derogatory, or negative messages to target persons based solely upon their marginalized group membership.” (p. 3). Microaggressions that occur on college campuses have an adverse effect on the academic performance, self-esteem, and mental health of students of color (Franklin et al., 2014; Nadal et al., 2014). Repeated exposure to microaggressions can also lead to racial battle fatigue, which can impact marginalized people at the individual and group level (Smith et al, 2016). Without addressing this form of racism, students of color will continue to feel marginalized on college campuses.

\section{Difficult Dialogues on Race}

Many scholars have suggested dialogue as a means to respond to issues of racism (Alimo, 2012; D’Andrea \& Daniels, 2007; Simpson, 2008; Sue \& Constantine, 2007; Sue, 2013). Simpson (2008) notes, "Dialogue at its best is an interaction among people that produces something greater than the sum of its parts and leaves participants changed by that interaction" (p.139). The process of dialogue itself is valuable, not just as a means to reach a solution (Heath et al., 2006; Simpson, 2008). It allows participants to challenge their preconceived notions and create shared meaning with one another, even if an action plan is not created. Successful dialogue also requires that its participants be willing to engage, suspend their own beliefs, and seek to understand those with different perspectives (Heath et al., 2006). Inspired by Buber, scholar Barnett Pierce thinks that the balance within dialogue can be sought if one can find a 
balance between "standing your own ground and being profoundly open to the other" (Heath et al., 2006, p. 345).

Allen (2007) points to deficiencies across the communication discipline in addressing issues of race, noting that more attention must be paid because race is "an enduring and contested phenomenon with important implications for communication studies, and for transforming society” (p. 259). Halualani, Fassett, Morrison, and Dodge (2006) add:

In communication studies, race has been analyzed mostly in critical rhetorical studies as a discursive, power-laden construction and in intercultural communication as both an identity-based category and an ideological construction of meaning. With such divergent paths, there remain fissures in the communication study of diversity and race. (p. 73). In their synthesis of applied communication scholarship that addresses race, Orbe and Allen (2008) offer important suggestions for extending such research: going beyond "explicitly racialized settings," addressing issues of intersectionality, promoting engaged scholarship, and taking a social constructionist perspective. Stories and narratives also provide an opportunity to bring together structural constructs of race and the lived experience (Halualani, et al. 2006). Luckily, structured difficult dialogues provide a platform for these types of communicative actions to take place and move productive conversations about diversity forward.

Although difficult dialogues can take many forms, those that center on issues of race and difference can be particularly complex and difficult to manage (Gayles, Kelly, Grays, Zhang, \& Porter, 2015). Unfortunately, there are few empirical studies on dialogue that capture the "lived and embodied realities of race" (Norander \& Galanes, 2014, p. 346). Such conversations also become limited when diversity is talked about in the abstract, which can limit the very material consequences of the lived experience (Norander \& Galanes, 2014). Such dialogue is also 
affected by White individuals' discomfort with talking about racism or defensiveness, as well as fear of tokenism experiences by people of color (Gayles et al. 2015). Black and Wiederhold (2014) highlight the benefits of public dialogue events to facilitate conversations about public issues and "promote mutual exploration and appreciation of diverse perspectives" in a structured and egalitarian format (pp. 285-286). That being said, the authors also note that managing the tensions around difference in these circumstances can be difficult for participants.

Conversation can lead to a greater breadth of knowledge regarding oppression, privilege, and power and a better appreciation of the "other" and different experiences, with the aim that "improved understanding will hopefully lead to actions that will challenge racism in all of its forms" (Gayles et al., 2015; Miller \& Donner, 2000, p. 34). Sue (2013) adds that constructive conversations have a positive effect on both the cognitive and emotional level and "have the potential to heal racial and ethnic divides, reduce prejudice and misinformation, and foster improved race relations" (p. 664). In particular, White students are able to confront their own biases and open up to the opportunity of becoming allies (Alimo, 2012). They typically have the hardest time discussing racism and minimal understanding of racial microaggressions. White participants fear appearing racist, realizing their racism, confronting White privilege, and taking personal responsibility to end racism (Sue, 2013; Sue \& Constantine, 2007). Unlike other initiatives that seek to address racism and microaggressions in these campus contexts, difficult dialogues are unique in that they provide multiple voices, at different levels, the opportunity to enter the conversation. Instead of a prescriptive response created by the university, these dialogues are a collective process that allow many people to be involved in addressing racismbased issues and constructing a solution.

Although the benefits of dialogue about racism have been outlined clearly, so have the 
challenges associated with these forms of communication. When handled incorrectly, dialogue can exacerbate the same emotions that perpetuate misunderstandings, including anger and silence, as well as create tension, anxiety, and awkwardness (Gayles et al., 2015; Sue \& Constantine, 2007). While students with dominant cultural identities may feel uncomfortable, minorities may feel tokenized (Gayles et al., 2015). However, if handled well, "race talk can improve communication and learning, enhance racial harmony, increase racial literacy, and expand critical consciousness of one's racial/cultural identity" (Sue, 2013, p. 663).

\section{Social Identity and a Goal-Based Approach to Racial Dialogues}

Our approach to facilitated dialogues on racism is also informed by social identity theory, which distinguishes between majority and minoritized groups, an important distinction in dealing with racial issues that often create tensions between majority and minority perspectives. Social identity theory, one of the major theories used to explain identity, postulates how group processes help people define who they are. It emphasizes that a social category in which someone belongs and feels they belong to defines who someone perceives themselves to be (Hogg, Terry, \& White, 1995; Tajfel \& Turner, 1979). By understanding themselves through a social category, individuals use their own self-definition of what it means to be part of a social group and further apply that understanding to themselves, influencing how they perceive outgroups and regulate the self in various contexts (Hogg et al. 1995).

Prior intergroup relations, awareness about existing stereotypes, and situational factors such as amount of structure and group composition influence the level of anxiety felt by participants in intergroup settings (Pettigrew, 1998). Intergroup interactions often lead to negative psychological outcomes, such as discomfort and frustration. Outgroup members may fear negative evaluations, including ridicule, disapproval, and disdain. While marginalized group 
members are usually most anxious about reinforcement of negative stereotypes and reproduction of power differences through discrimination and erasure, members of dominant groups are often concerned about being perceived as prejudiced.

Some of the challenges that this research brings to our attention are that people of color are much more likely than White people to be conscious about and think about their racial identity in intergroup interactions (Nagda, 2006). Dominant group members are likely to approach diversity and difference by emphasizing harmony rather than conflict and the personal rather than the political. They are also likely to invalidate, question, and challenge marginalized groups by taking control of the conversation, which can lead to estrangement rather than engagement (Nagda, 2006). Given this understanding of social identity theory, dialogue design must consider racial composition of participants and the potential impact of related contexts on the way dialogue is approached and managed.

\section{The Present Study}

This paper fills an important gap regarding the ways in which dialogue can be used to address conflict and in particular, race-related incidents on college campuses. It draws on existing literature on use of dialogues in difficult scenarios (D’Andrea \& Daniels, 2007), communication research on race and difference (Allen, 2007; Halualani et al. 2006, Orbe \& Allen, 2008), and the role of social identity in dialogical contexts (Nagda, 2006) to help design facilitated dialogues on campus racism. Our aim is to share insights about the goal-based dialogical framework we developed as tools for universities to address similar incidents on their own campuses. Racist incidents like these continue to challenge the values of universities and their many publics, and arguably could happen more so in the current political climate. Understanding the power of dialogue can help to address these issues and give the campus 
community an outlet to discuss and cope with such events. Based on the context, literature that we have reviewed, and the theoretical framework that we draw from, we pose two research questions that will be examined:

RQ1: What are the communication design elements that help facilitate difficult dialogues on campus race relations?

RQ2: What were the perceived impacts of these difficult dialogue sessions?

This case study is presented in two parts. Part I addresses the theory-based communication design decisions that shaped the facilitated dialogues on campus race relations. Part II discusses the perceived impact of these sessions based on our analysis of participants' feedback and other indirect indicators.

\section{Part I: Session Design}

When the racist incident occurred at the historically White Southern university in early 2016, diversity leaders on the campus got together to discuss ways to be proactive in addressing such microaggressions on campus in the future. At that time, there were few existing opportunities for students to digest what had happened or to have a forum to discuss what could be done about such incidents on campus. The College of Liberal Arts stepped in and designed a series of "difficult dialogues on campus race relations" where students, faculty, and staff could do just this. These sessions had to be enacted quickly to respond in an appropriate timeframe after the incident. The initial purpose of these dialogues was to serve as an educational resource to the campus community. Therefore, the emphasis was more on the design of the dialogue sessions rather than on impact and assessment. As sessions continued to be held throughout the year and positive feedback was received, it became clear that there would be valuable theoretical and practical implications for communication scholars. 
The design of the difficult dialogues was informed by prior research on communication as design and liberating structures (Aakhus, 2007; Aakhus \& Bzdak, 2015; Lipmanowicz \& McCandless, 2013). As Aakhus and Bzdak (2015) explain, "communication design highlights communication practice aimed at crafting preferred communicative activities out of a given situation and thus the manner through which people interact and reason together" (p.

191). Aakhus (2007) states, "Where other approaches to communication focus on the behavior that occurs within a communication format, design focuses on what those formats presuppose about communication and with what consequence the new format is taken up in communicative practice" (p. 114). Similarly, the liberating structures perspective also emphasizes the role of design in fostering open discussions on seemingly difficult and impossible topics. The key principles here include the structuring of the invitation to focus on a specific issue, arranging the space in an open setting conducive to dialogue, providing equal opportunity for everyone to participate, configuring groups in manageable sizes to fit the goals of the discussion, and paying attention to the sequence of activities and the time to be allocated to them (Lipmanowicz \& McCandless, 2013).

Keeping the central principles from these theoretical perspectives in mind, we designed our sessions using a "round table" format, with 6-8 people per table for small group discussions. Those with training and experience with conflict management, difficult dialogues, and diversity education were recruited to serve as facilitators. They were provided a brief training to orient them to their roles and responsibilities as facilitators. Facilitators were included to create an environment where power asymmetries can be reduced, personal narratives relating to their social identities can be shared, and opportunities can be created for improving intergroup relations. Because of our recruitment strategies, some of the sessions turned out to have 
predominantly White participants and others had predominantly minoritized participants of color. Nonetheless, we made each small group as diverse as possible by grouping together people of different races, genders, and ages, and by asking participants to avoid sitting with people they knew. Guided by prior research on social identity theory, we used a goal-based approach to design our sessions slightly differently for these two types of groups. Those who had experience with racism on campus were able to air their grievances and have a venue to be heard, while those who were being confronted with these issues for the first time were also able to be honest about the revelations they had made.

\section{Common Design Elements across Groups}

Ground rules. Ground rules are important as prior research on race and intergroup dialogues suggests that discussions on racism can be challenging, awkward, and sometimes lead to misunderstandings, anger, and silencing (Gayles et. al, 2015; Sue \& Constantine, 2007). White participants are sometimes anxious to avoid appearing prejudiced and participants of color are often concerned about erasures, reproduction of power differences, and tokenization. Our difficult dialogues begin with a set of ground rules, an agreement among group members meant to ensure the effectiveness of conversation. The following guidelines were discussed with and agreed upon by our participants before we began the dialogues: active listening, balanced air time, confidentiality, assume good intentions and make "I" statements. These ground rules were important as they helped to set the tone of the dialogue to be open and respectful conversations. Participants all verbally agreed to these ground rules, and facilitators stepped in when necessary to ensure the ground rules were abided by.

Journal entries. As suggested by Halualani (2006), stories and narratives play an important role in bringing lived and embodied experiences of race into difficult dialogues on this 
topic. Rather than discuss diversity and race relations in the abstract, we decided that groups would begin by reading a series of personal journal entries kept by participants for a Sociology course that had students document when they witnessed or experienced racism at the university. Keeping the case studies localized to our university was a deliberate choice because we wanted participants to connect with and reflect on the everyday lived realities of racism on their campus. About 30 such vignettes were included in the packet to show the range and prevalence of racist incidents on campus. These vignettes included a range of microaggressions, including microinsults, micro-assaults, and micro-invalidations (Sue et al., 2007). An example journal entry included:

My friends were having a poker night, and the rules of the party were posted on the wall. There had to be more girls than guys, and there had to be all White girls. I asked my friend why there were only White girls, and he said, well we don't want any of those nasty girls, and I said they weren't nasty, and he said, "Well they just aren't my type. Participants silently read and reflected on these vignettes, and then were prompted by facilitators to share their reactions within their small group. In this way, participants worked through their own emotions regarding the real-life stories and also listened to others' reactions.

Prompts for guided small group discussions. Because we wanted the participants to not just recognize that racial microaggressions exist on campus but also have them collectively think about individual and collective change, we selected three focused questions for the small group discussion that led to the large group discussion: "What were your/your group's thoughts and feelings as you read through these journal entries?" "Which of these entries impacted you/your group and why?" and "What can we do individually and collectively to improve race relations on campus?" As Alimo (2012) suggests, it is crucial that such conversations not only offer 
opportunities to confront personal biases but also allow participants to move on to discussions about allyship and alliance-building.

Wrap-up and call to action. The dialogues ended with a discussion about what the sessions' participants could do when they left. They were given tips about how to spot racism and micro-aggressions, how to give micro-affirmations, and how to speak up. Several different types of microaggressions such as racist jokes, slurs, non-inclusive language, threats, social distancing and physical threats were discussed. Based on work by Goodman (2011), we offered six different strategies - echoing back, questioning, playing dumb, challenging stereotypes, highlighting commonalities, and expressing your feelings - as tools to respond to microaggressions as bystanders and victims. We explained that, before a racist incident even happens, micro-affirmations are positive words that can be used to increase feelings of adequacy and self-worth (Rowe, 2008). In order to "Be the Change," participants were given a handout of how to improve race relations, a hashtag and bracelet with the commitment "I won't be silent," website resources to report racism and discrimination, and were asked to make a personal commitment to improve race relations on campus. The handout included ten practical ways in which individuals can work to improve race relations in society (Gallagher, 2011).

\section{Design Differences across Groups}

Prior literature helped us understand that minoritized groups and dominant groups differ in how they approach dialogues on race relations (Gayles et. al, 2015; Nagda, 2006; Sue \& Constantine, 2007). With White participants, our goal was to build empathy through active listening, while with minoritized participants of color we focused on strategies to combat racial microaggressions. Based on our understanding of these differing goals of participants, the sessions with more White participants were designed to be slightly different from those with 
mostly participants of color. Table 1 describes the common and unique communication design elements across groups.

\section{[Insert Table 1 about here]}

Sessions with majority White participants. In these sessions, we started by screening a video by the white male Student Body President condemning the racial harassment and emphasizing the value of respect. This was followed by an ice breaker session for participants to introduce themselves and share their favorite smell, something they are afraid of, and a place they'd like to visit. This activity was important to diffuse any anxieties typical of intergroup communication settings and get the participants to start opening up with strangers. Next, we provided ground rules and explained how every ground rule was intended to facilitate discussions on race. We asked that everyone, after hearing the ground rules, commit to adhering to them. In order to drive home the point that racism exists, we asked each group to silently read local vignettes then discuss their reactions to them as a small group. We stationed a trained expert facilitator at each table with the participants in order to keep participants on topic, ensure everyone had a chance to speak, and ensure discussions followed ground rules. In this way, shy participants were able to speak about their experiences with racism, and talkative participants had a chance to hear others' perspectives. The groups also discussed the actions they could take to address campus racism, and one spokesperson from each group presented their suggestions to the entire group of participants.

Sessions with majority participants of color. The mixed race sessions with more participants of color tended to already be aware of campus racism. They were keen on better understanding how to combat racism and how to assist others who could encounter microaggressions. We did not include an ice breaker activity or expert trained facilitators for the 
small group discussions in these sessions because these students expressed greater solidarity and shared goals of supporting one another. There was not much anxiety that had to be reduced using the ice-breaker and participants adhered to the ground rules without the presence of a trained facilitator for the small group discussions. Two facilitators walked around the room while groups talked, but were not needed at the small group tables to guide discussions. We incorporated a role-play exercise where each group chose a vignette and enacted a scenario. If there was vulgar language in the vignette, we asked that they leave that out. Importantly, after reenacting a vignette, the participants acted out how they would respond to instances of racism. In this way, we used role-play to bring the vignettes, and ways to respond to racism on campus, to life. We decided to reveal techniques for addressing difficult dialogues after, rather than before, the role play activity because we wanted the participants to think creatively. We believed participants would retain techniques more if the groups first worked at and perhaps had difficulty with coming up with ways to respond to situations. We talked as a whole group about the role-play activity and techniques the participants could use in the future.

\section{Part II: Perceived Impact of Sessions}

The difficult dialogue sessions on campus race relations were well received by participants and the campus community at large. Below we analyze participants' written feedback to examine patterns relating to their perceived impact, overall satisfaction and the main learnings from these sessions. Later in this section, we share other indicators of impact beyond participants' feedback forms.

\section{Participants}

The dialogue series was mainly intended for students, but faculty and staff could also join. Eight such sessions took place between March 7, 2016 and November 3, 2016. For four of 
the sessions, participants were recruited through an open call sent out to the university's list-serv that reaches all students, faculty, and staff. The purpose was to invite individuals with diverse experiences, attitudes, and backgrounds to engage in these difficult conversations. Preregistration was required. We asked participants who arrived together to sit at different tables and requested that each table be made up of different races, genders, and people who did not know each other prior to entering the room. Given the success of the open-call sessions, we were invited to lead four other sessions with intact groups (such as student organizations, student leadership conferences, and specific courses).

Although we did not intend to separate groups based on racial/ethnic identity, because of the recruitment differences (open calls versus invitations), we ended up with six sessions with majority White participants and two sessions with mostly participants of color. It is to be noted, though, that all sessions had a variety of racial/ethnic group participants, even if the proportions varied between majority White and majority non-White groups. Overall, our sample consisted of White (31\%), Latinx (24.8\%), Black/African American (23.65\%), Asian (9.3\%), Middle Eastern/North African (1.55\%), Native Hawaiian/Pacific Islander (.77\%), American Indian/Alaska Native (.38\%), Biracial (6.58\%), and Multiracial (1.16\%) participants. Of the 170 who completed forms in the majority group sessions, $45.9 \%$ were Whites, but there were also Black (14.7\%), Latinx (19.4\%), Asian (11.8\%), Middle Eastern (1.8\%), American Indian/Alaskan Native (0.6\%), and Biracial (4.7\%) participants. Of the 88 in the minoritized groups, participants were mainly Black (40.9\%) and Latinx (35.2\%), but also included Asian (4.5\%), Biracial (10.2\%), White (2.3\%), and Multiracial (3.4\%) participants.

Sessions included mainly undergraduate students (52.7\%) and graduate students (27.9\%), though there were a few faculty members $(2.3 \%)$ and staff members $(2.7 \%)$ who also 
participated. Because one of the minoritized participant sessions was conducted as part of a graduate students of color symposium, this session had predominantly graduate students (55.7\%) as opposed to undergrads $(2.3 \%)$ while the majority group sessions had more undergraduate students (78.8\%) as compared to graduate students (13.5\%). Participants came from a variety of majors and colleges.

\section{Feedback Forms}

At the end of each session, participants were asked to fill out a feedback form. Of the 328 participants who participated in these sessions, 258 of them completed the feedback forms (a $78.6 \%$ response rate). The response rates were much higher for the sessions with majority participants of color (97.7\%) as compared to the majority White sessions (71.4\%). The quality of responses were similar across all groups, with almost all respondents answering all questions, including the open-ended ones, even if they only wrote one or two sentences.

Our open-ended feedback forms prompted respondents to write in their race/ethnicity, which college they are affiliated with, and their classification as undergraduate, graduate, faculty, or staff. In addition to basic demographics, we asked respondents what they learned, if they felt they had adequate resources to engage in race discussion before and after the session, and if they would recommend this session to others. Specifically, the form included open-ended questions such as "What did you learn from today's session?" "After the discussion, do you feel you have adequate resources to engage in discussions regarding race and racism on campus? Please explain your answer," "Would you recommend this session to others? Why or why not?" and "Do you have any other thoughts or comments?"

\section{Data Analysis}

We analyzed cross-tabulations and reported percentages across groups for the close- 
ended questions on demographics, whether the participants gained adequate resources through the sessions, and whether they would recommend these sessions to others. For the open-ended questions on the feedback form, common themes were coded across sessions of the same group type. To begin this process, open, first-level coding was done to identify relevant themes. Coding was done iteratively, an approach offered by Tracy (2013) that allows the process to be driven by existing literature and theory, but in a way that also allows themes/codes to emerge naturally. Once relevant codes were identified, the open-ended questions were coded a second time and representative examples and comments were pulled for analysis. After sessions for the two types of groups were coded separately, a comparative analysis between the two types of groups was done to assess the similarities and differences between the two goal-based groups. In particular, we were concerned with examining questions that sought to parse out what participants learned from the dialogues, why they would or would not recommend a similar session to others, and if they had additional thoughts.

\section{Overall Satisfaction with Sessions}

$97 \%$ of majority group participants and $94.3 \%$ of minoritized group participants reported that they will recommend the session to others. Those in the majority group sessions were most likely to say yes $(87.6 \%)$ compared to no $(2.9 \%)$, undecided $(5.3 \%)$ and neutral $(3.5 \%)$ on whether they have adequate resources to engage in discussions regarding race and racism on campus after attending this session. Those in the minoritized group sessions responded reported $75 \%$ yes compared to no $(4.5 \%)$, undecided $(6.8 \%)$, and neutral $(12.5 \%)$.

\section{Common Perceptions across Groups}

Our analysis of open-ended questions revealed several common themes that emerged around the importance of having open dialogues on racism, standing up against racism, and 
learning new strategies to combat racial microaggressions.

Importance of open dialogues. The emphasis on dialogue was appreciated by the participants as it facilitated active listening, empathy-building, and open conversations. Some representative quotes are: "It gives people ways to express their viewpoints and to hear others, while learning ways to positively express themselves," "I feel changed by hearing others' own personal stories with race. I want to make sure not to tolerate or overlook hurtful [comments] and forget the valuable opinions and reflections I had today." These responses indicate that participants felt comfortable sharing their experiences in the venue we provided, were receptive to others' perspectives, and gained new understanding of experiences that differ from their own.

Standing up against racism. Another theme was that it is important to speak up against racism. Some sample comments are: "Thank you-Very emotional topic, but I feel like my voice to speak up against racism is valid now," “We need to speak up. People need to be educated. This is a problem," and "[I learned about] being a voice - not just standing by and watching." Participants felt their voices were heard and validated, recognized the importance of speaking up, and took what they learned to the next level by compelling themselves and others to stand up against discrimination.

Tools to confront racial microaggressions. Several participants indicated that they learned about microaggressions for the first time during the sessions and gained a greater understanding of explicit versus implicit racism. Some examples of such comments are: "Tonight has given me many resources to use and pull from to better prepare myself," and "Gained feedback on ways to discuss these issues and new strategies on how to accurately combat discrimination/bias." These comments reveal that participants believe they were provided with tools to fight racism, and are more likely to do so since they know strategies for 
standing up to discrimination.

\section{Group-Based Differences in Participant Perceptions}

Although both groups recognized the importance of raising awareness about racism and speaking up against it, there were distinct differences in how they approached these issues.

Sessions with majority White participants. For the majority White participant sessions, telling themes included surprise about the prevalence of racism, speaking up for others, and the importance of allyship.

Surprise about the prevalence of racism. Participants in the majority White participant sessions were overwhelmingly "shocked" by the widespread racism expressed in the journal entries. They repeatedly used certain words when explaining their experience: "insightful," "eye opening," "informative," and "awareness." They wrote that they learned: "How real and serious incidents take place. It's more frequent than I thought," "Being a White girl, I was surprised at many of the journal entries, since I am not normally exposed to racism," "A lot of realization of what is really going on - looking outside my little bubble." White participants took a step towards understanding racism by first recognizing that it currently exists; they acknowledged that these experiences (which many participants of color were not surprised by and/or experienced themselves) are not obvious to them yet still occur.

Speaking up for others. The importance of speaking up for others was the most notable response and mentioned in some form by over 30 participants. Examples included: "Speak up for others, with confidence," "Don't be afraid to speak up for someone of a race that is different from you," "[I learned] the importance of standing up for people who don't look like me," and "I

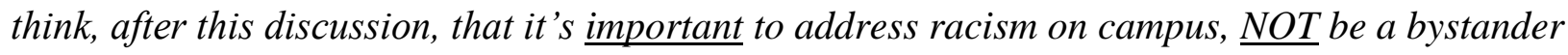
and to encourage staff to promote more classes." Participants who were previously reluctant to 
speak up against injustices now indicate feeling empowered to use their voice to support others who are different from them.

Importance of allyship. Minority participants in these sessions highlighted the importance of having allies and the opportunity of dialogues such as these to help them recognize they exist. As one Black staff member explained, "[I learned] not to drop the fight and I'm not alone." A Black undergraduate noted, "There are more allies on this campus than I imagined." Similarly, many White participants also came to realize their own positionality in recognizing racism and making a difference. Both White participants and participants of color recognize the benefit of coming together and indicate the importance of unity.

Sessions with majority participants of color. These participants shared several unique experiences including feeling validated, the importance of individual and collective responsibility, increased self-efficacy to combat racism, and recognizing differences within minoritized groups.

Feeling validated. The localized vignettes about racial microaggressions "rang true" and validated their own personal experiences on campus. Rather than the sense of surprise or shock about the existence of racism, the vignettes gave participants of color a sense of confirmation that campus racism was systemic rather than only their own personal experience. Some examples of such comments were: "Know that you're probably not the only one who felt that way," "There are people around you that have been in your shoes," and "[I learned] that many people have gone through similar experiences. " Participants no longer felt isolated; rather, their lived experiences were affirmed. These reactions also indicate the pervasive nature of such discriminatory incidents.

Individual and collective responsibility. Another notable pattern was the emphasis on 
personal responsibility for combating racism. Participants noted, "We all have a personal responsibility to stand up," "Yup, I don't care what people think. I'll just speak up despite my emotions," "I learned, yet again, how people of color can stand up for ourselves," and "When in a group, it is easier to stand up for yourself and others." These responses show that participants felt empowered to stand up for themselves and for others, and that educating others is a responsibility shared by all.

Increased self-efficacy to combat racism. Many participants noted learning tools to confront microaggressions and that a good place to start making a difference was in one's own social circles. Sample comments include: "I had a familiarity with the situations presented today enough to engage in good conversation, but the presentation did help out a lot in giving techniques to go about addressing certain situations," "Role play scenarios help show me what I can do in real life situations," and "There are many strategies, including microaffirmations to start reflective, respectful conversations.” Participants indicated being more likely to address discriminatory circumstances because they felt better prepared to handle these situations.

Recognizing differences within minoritized groups. Several minoritized participants highlighted how experiences within their groups with racism are also diverse and the importance of addressing these differences with respect. Participants noted: "Each cultural group has their own struggles," "[I learned] to accommodate everyone from different backgrounds to speak up against racism," "[I learned that] everyone has a different view on racism, privilege" and “......racism comes in all shapes and sizes and just because a person's experience is different than yours does not mean they didn't experience racism." In addition to recognizing racism, participants see how discrimination appears differently for various minoritized groups.

\section{Constraints and Limitations of Facilitated Dialogues}


Although overall the feedback was overwhelmingly positive, there were several points of variability in the extent to which participants were willing to get out of their comfort zones to actively listen to other perspectives. Although negative responses were few, they are important to consider while adjusting dialogues to meet the needs of our participants' diverse experiences.

Need to address systemic racism. Participants of color sometimes reported that the sessions could do more to engage in conversations about systemic and structural racism. A Latinx participant noted that dialogues like these were more of a "cosmetic change" and when asked for his/her additional thoughts stated, "Please consider what you can do as an organization to PROTECT students, faculty, and staff of color on this campus." A Black student felt that the session didn't teach them how to "enact real change." Others wrote: "[I learned] that as a college we can talk about racial issues as a student body but are not given a 'what do we do next,", "This was a good reminder. I'd like to know what the university is doing as well. I feel the university's response is weak" and "Please let us know what you are doing, especially how you are teaching ignorant Whites to open their minds." These comments highlight the general reflection that dialogue is only a part of what should be a far-reaching and multi-layered approach to systemic racism.

Difficulty in perspective-taking. Some participants were frustrated with the dialogue process, highlighting why racial conversations can be especially hard for some individuals. For instance, a participant from a minoritized group session wrote: "Taking perspective of another continues to be a struggle while communicating" and that they learned "nothing new." A couple of White participants were resistant to acknowledging racism. They steered the conversations toward reverse racism. For instance, one participant's feedback form said, "Racism does exist against the white race, but wasn't discussed as much because they are the majority. (Whites are 
trained to feel ashamed for their "white privilege")." When a facilitator pointed out the colorblind racism being expressed by a White female participant, another participant wrote, "I thought implying that the woman's comment was racist was in fact racist of <name of facilitator $>:-($ Too easy to throw that word around, not right to throw it around irresponsibly." Some participants who had trouble seeing another's perspective, were disappointed by the emphasis on racial minorities, or felt their own voices were silenced. Our goal was to open dialogue for everyone involved and increase awareness of discrimination, and so we considered this feedback when determining how to continue effective difficult dialogue sessions.

\section{Other Indicators of Impact}

Apart from participant feedback forms, there were other indirect indicators of the impact of our initiative. The local student newspaper covered our sessions, which garnered attention from the larger student body. We were invited to conduct these sessions for student diversity leaders, a freshmen mentoring organization, a student conference for graduate students of color, and a course on music and diversity. Some participants were inspired to create a musical performance based on their experiences in our session and have archived it on YouTube. We received a competitive internal grant to conduct research on this project. The university has invited our team to create online diversity modules on "Ground rules for facilitating dialogues" and "Recognizing and combating racial microaggressions" to serve as resources for instructors on our campus.

\section{Discussion}

This project aimed to examine how social identity shapes critical communication design elements that help in facilitated dialogues on race relations. We were interested in understanding how these dialogues about race relations and racism impacted participants in terms of raising 
awareness about racism, building empathy, and providing tools to combat racial microaggressions.

Our findings point to the importance of taking into consideration social identity theory, differences in lived experiences, and differing goals in designing intergroup dialogues, especially on challenging topics such as race relations. Specific communication design elements such as localized case studies, shared ground rules, expert facilitators, and role-play affect the nature and outcomes of dialogue sessions. Our study builds upon and extends the existing literature on race, communication, and dialogues by suggesting that rather than discuss racism as an abstract concept, having participants read and discuss a variety of localized vignettes with a range of racial microaggressions is particularly powerful. While selecting such vignettes, it is preferable to include not just micro-assaults but also subtler micro-insults and micro-invalidations.

Additionally, this project connects the scholarship on social identity, intergroup dialogues, and communication design by emphasizing the importance of designing dialogue sessions by keeping the identity and related goals of the participants in mind. Understanding the context (e.g. participants, group facilitation) in which conversations will occur and the goal of dialogue is critical when considering design (Miller \& Donner, 2000). Barge and Little (2002) challenge scholars to look at dialogue as more than just highly structured, "abnormal" forms of communication. Their Bakhtinian approach is offered as "a starting point for further conversation and research into the kinds of communicative practices that will support the development of [sensibilities of wholeness, uniqueness, and emergence] in conversation" (p. 395). Different kinds of dialogue produce different results, and such considerations should be taken into account as these types of initiatives are designed.

In our case, established ground rules and small group facilitators were crucial design 
aspects to include in majority White participant sessions, given their general lack of knowledge of racism and to ensure that they do not replicate power differences by dominating the conversations. Facilitators in these sessions were meant to coax responses that may have been hesitant to emerge because of the topic of conversation and to keep the dialogue balanced and respectful. Their presence helped to clarify why each ground rule was in place and ensure that the participants respected all of the ground rules laid out.

A highly structured format was less necessary for participants of color sessions because of their shared identities. Their ideas were able to flow quickly as they piggybacked off of one another because they did not need to partake in such an extended amount of cognitive labor to determine how they would be received by their group members. It was sufficient to allot less time to reading the vignettes, since they were often already aware of racial microaggressions. As we expected, the minoritized group session participants were ready to take on the challenge of role-playing various scenarios from the journal entries and engaged with the materials deeply. The role play activity helped participants practice the strategies in their simulations of real-world vignettes and such collaborative hands-on learning was particularly powerful. More research is needed to understand the impact of role-play activities in facilitating difficult dialogues.

In terms of the perceived impacts of the sessions, participant feedback and other indirect indicators suggested that the sessions were able to raise awareness about racism and racial microaggressions on campus. Participants repeatedly used specific terms such as "eye-opening," "greater understanding," "became more aware," in describing their experiences. White participants were largely able to engage in critical self-reflection, become more conscious about social inequalities, and build empathy towards those experiencing discrimination. These sessions allowed participants from majority groups to encounter "otherness" in a profound way, utilizing 
the transformative power of dialogue (Simpson, 2008) and responses reflected this. Dialogue is effective for promoting the values of diversity and inclusion, and can have lasting effects for those involved (Gayles et al., 2015). For participants of color, such conversations allowed for open sharing of their personal experiences without judgment and coalition-building for collective and individual action against inequalities. Participants in both groups also pointed to the possibility of increased self-efficacy, responding that they were more likely to "speak up," and "not be silent." While majority White groups emphasized the importance of such initiatives, minoritized groups understood dialogue as only a piece of the puzzle and many sought more. This was not a surprising finding, as the literature on dialogue points to difficulties negotiating conversation and action. As Norander and Galanes (2014) note, "Dialogic organizing is both a process and a product of communicative practice......this can frustrate participants who view further talk as a poor substitute for action or as a means to delay social action.” (p. 348)

Dialogue is an important component of addressing racism and microaggressions on campus, but should be coupled with other initiatives. Towards this end, it was essential that the wrap-up activity provided specific resources that participants could engage with in terms of future action. At the individual level, six different verbal strategies (Goodman, 2011) and microaffirmations (Rowe, 2008) were suggested as a positive and preventive strategy to counter microaggressions. At the collective level, ten steps that could be taken to improve race relations were shared as an additional reading material (Gallagher, 2011). These strategies and tools for further action are likely to be especially appreciated by minoritized participants.

\section{Practical Implications}

This research serves as a resource for diversity leaders in other universities, especially historically White institutions, which are looking for ways to create more spaces for open and 
honest conversations about race and racism, at a time when racial tensions are high with increases in racially-motivated hate crimes in the U.S., including on campuses. Our goal-based difficult dialogue model can serve as a framework to engage with and listen to campus community members on a variety of difficult and complex topics such as experiences with sexism, social class-based differences, first-generation student challenges, xenophobia experienced by international students, discrimination against LGBTQIA students, and hate expressed towards religious minorities. Such conversations should be designed mindfully, with inputs from communication experts and diversity leaders apart from the feedback received from participants themselves. Most of all, it is essential that such dialogues avoid reproducing the same structural inequalities that lead to discrimination and racism in the first place.

These findings also have implications for several applied settings beyond academe. Several business organizations in White-dominated occupations in particular have placed a greater emphasis on diversity and inclusion, not just in terms of recruiting more racial/ethnic minorities but also finding ways to help them succeed and thrive. An important aspect of building community, be it in business or other types of organizations, is to create an open welcoming climate where employees and coworkers feel comfortable to have honest conversations about important yet challenging topics. Diversity literacy is an integral aspect of successful leadership and citizenship education. These sessions promote important skills such as active listening, empathy for others, and openness to diverse viewpoints, which can be applied to a variety of community and organizational settings.

\section{Limitations and Directions for Future Research}

While these difficult dialogues raised awareness about the prevalence racism, building empathy toward others, promoting active listening to diverse perspectives, and increasing self- 
confidence in combating racial microaggressions, they were not perfect. There was considerable variability in knowledge, competence, and engagement with the dialogues across groups and participants. There were tensions that made these discussions challenging and difficult at times, especially while participants discussed the role of dialogue versus concrete actions, reverse racism against Whites, color-blind racism, and frustration with the perceived lack of perspectivetaking among other participants. Future sessions can incorporate more resources about collective action to combat such structural racism at the institutional and organizational level that goes beyond the interpersonal level.

An important limitation is the self-selection bias in sampling. Presumably, those who attended these sessions were already open to having such dialogues. However, we included participants from multiple racial/ethnic backgrounds in all our sessions without separating groups based on racial/ethnic identity. This was an important decision because by definition, difficult dialogues are successful when they bring people from differing backgrounds and attitudes in contact with one another. The minoritized group sessions happened to have more graduate rather than undergraduate students, which limits generalizability of the findings.

Ideally, we would have also liked to offer these sessions as a series of dialogues that would build upon one another. Future diversity educators and communication practitioners might want to consider hosting several such sessions with the same participants to go into greater depth about various types of biases, levels of discrimination, and strategies to combat them. Because our difficult dialogue sessions were intended as a pedagogical rather than a research intervention at the start of the project, we were limited by the data collected in feedback forms. More in-depth questionnaires using field experimental research methods in the future would yield greater confidence in the effectiveness of the dialogue designs in influencing participant perceptions. 


\section{Conclusion}

In sum, our findings suggest that dialogues play an important role in facilitating conversations among members of diverse groups on difficult topics such as racism. It is important to take a goal-based social identity approach to designing such dialogues by selecting appropriate communication design elements (such as localized vignettes, shared ground rules, trained facilitators and role-play techniques) to suit the differing needs and goals of the racial/ethnic identities of the participants. Difficult dialogues, like the ones presented here, are a good first step in addressing racism on campus. These dialogues open up the ability for participants to discuss racism and other controversial topics and, combined with other methods of combatting racism, are an avenue for change. When designed well, such racial dialogues can encourage critical thinking to reflect on diverse perspectives, create greater empathy among majority participants for experiences of minoritized people, help form alliances across multiple groups to work collectively towards a common goal, and motivate participants to make a personal commitment to be agents of change within their circles of influence. 
Table 1

Goal-Based Dialogue Design Framework

\begin{tabular}{|c|c|c|}
\hline & $\begin{array}{c}\text { Majority White Participant } \\
\text { Sessions }\end{array}$ & $\begin{array}{l}\text { Minoritized Participants } \\
\text { of Color Sessions }\end{array}$ \\
\hline Session/Participants & 6 sessions, 170 participants & 2 sessions, 88 participants \\
\hline Goals & $\begin{array}{l}\text { Empathy building, raising } \\
\text { awareness about racism; active } \\
\text { listening, critical thinking }\end{array}$ & $\begin{array}{l}\text { Empowerment, sharing } \\
\text { personal stories, collective } \\
\text { and individual action to } \\
\text { combat racism }\end{array}$ \\
\hline Common Design Elements & \multicolumn{2}{|c|}{$\begin{array}{l}\text { Localized case studies; shared ground rules, small and large } \\
\text { group discussions; wrap-up session and call to action; } \\
\text { feedback forms }\end{array}$} \\
\hline Unique Design Elements & $\begin{array}{l}\text { No role play activity; small } \\
\text { group trained facilitators; ice } \\
\text { breaker activity; greater } \\
\text { emphasis on recognizing racial } \\
\text { microaggressions }\end{array}$ & $\begin{array}{l}\text { Role-play activity; no small } \\
\text { group facilitators; no ice } \\
\text { breaker activity; greater } \\
\text { emphasis on combating } \\
\text { racial microaggressions }\end{array}$ \\
\hline Common Outcomes & \multicolumn{2}{|c|}{$\begin{array}{l}\text { Suggestions for what we can do to combat racism; importance } \\
\text { of "speaking up" and not being silent; greater knowledge of } \\
\text { types of racism and microaggressions }\end{array}$} \\
\hline Unique Outcomes & $\begin{array}{l}\text { Focused on surprise and shock } \\
\text { surrounding extent of racism } \\
\text { that exists; highlighted the } \\
\text { importance of dialogues as a } \\
\text { way to learn more about } \\
\text { different people and stand up } \\
\text { for others; recognized the } \\
\text { importance of allyship; }\end{array}$ & $\begin{array}{l}\text { Emphasized importance of } \\
\text { education/awareness; } \\
\text { emphasized individual and } \\
\text { collective responsibility; } \\
\text { recognized differences } \\
\text { within minoritized groups; } \\
\text { increased self-efficacy to } \\
\text { combat microaggressions }\end{array}$ \\
\hline $\begin{array}{c}\text { Constraints and } \\
\text { Limitations of Dialogues }\end{array}$ & \multicolumn{2}{|c|}{$\begin{array}{l}\text { Need to address systemic racism, difficulty in perspective- } \\
\text { taking }\end{array}$} \\
\hline
\end{tabular}




\section{References}

Aakhus, M. (2007). Communication as design. Communication Monographs, 74(1), 112-117.

Aakhus, M., \& Bzdak, M. (2015). Stakeholder engagement as communication design practice. Journal of Public Affairs, 15(2), 188-200.

Alimo, C. J. (2012). From thought to action: The impact of cross-race intergroup dialogue on the development of white college students as racial allies. Equity \& Excellence in Education, 45(1), 36-59.

Allen, B. J. (2007). Theorizing communication and race. Communication Monographs, 74, 259264.

Barge, J. K., \& Little, M. (2002). Dialogical wisdom, communicative practice, and organizational life. Communication Theory, 12, 375-397.

Black, L. W., \& Wiederhold, A. (2014). Discursive Strategies of Civil Disagreement in Public Dialogue Groups. Journal of Applied Communication Research, 42(3), 285-306.

Boylorn, R. M. (2011). Black kids' (B. K.) stories: Ta(1)king (about) race outside of the classroom. Cultural Studies $\leftrightarrow$ Critical Methdologies, 11(1), 59-70.

D’Andrea, M., \& Daniels, J. (2007). Dealing with institutional racism on campus: Initiating difficult dialogues and social justice advocacy interventions. College Student Affairs Journal, 26(2), 169-176.

Elbushra, S. (2016, April 22). New group demands action from University. The Battalion. Retrieved from http://www.thebatt.com/news/new-group-demands-action-from$\underline{\text { university/article_34f6e4fe-0847-11e6-8359-73c022edafa4.html }}$

Franklin, J. D., Smith, W. A., \& Hung, M. (2014). Racial battle fatigue for Latina/o students: A quantitative perspective. Journal of Hispanic Higher Education, 13(4), 303-322. 
Gallagher, C. A. (2011). Rethinking the color line: Readings in race and ethnicity (5 ${ }^{\text {th }}$ edition). McGraw-Hill.

Gayles, J. G., Kelly, B. T., Grays, S., Zhang, J. J., \& Porter, K. P. (2015). Faculty teaching diversity through difficult dialogues: Stories of challenges and success. Journal of Student Affairs Research and Practice, 52(3), 300-312.

Goodman, D. J. (2011). Promoting diversity and social justice ( $2^{\text {nd }}$ edition). Routledge, New York.

Halualani, R., Fassett, D. L., Morrison, J., \& Dodge, P. (2006). Between the structural and the personal: Situated sense-makings of "race.” Communication \& Critical/Cultural Studies, 3, 70-93.

Hamer, J. F., \& Lang, C. (2015). Race, structural violence, and the neoliberal university: The challenges of inhabitation. Critical Sociology, 41(6), 897-912.

Hassan, C., Almasy, S., \& Valencia, N. (2016, February 12). Texas A\&M investigating reports of racial slurs toward high school visitors. CNN. Retrieved from http://www.cnn.com/2016/02/12/us/texas-am-racial-incident/

Heath, R. L., Pierce, W. B., Shotter, J., Taylor, J. R., Zorn, T., Roper, J., Motion, J., \& Deetz, S. (2006). The process of dialogue: Participation and legitimation. Management Communication Quarterly, 19(3), 341-375.

Hogg, M. A., Terry, D. J., \& White, K. M. 1995. “A Tale of Two Theories: A critical comparison of identity theory with social identity theory." Social Psychology Quarterly $58: 255-269$.

Lipmanowicz, H., \& McCandless, K. (2013). The surprising power of liberating structures: simple rules to unleash a culture of innovation. Seattle: Liberating Structures Press. 
Miller, J., \& Donner, S. (2000). More than just talk: The use of racial dialogues to combat racism. Social Work with Groups, 23(1), 31-53.

Minikel-Lacocque, J. (2013). Racism, college, and the power of words: Microaggression reconsidered. American Educational Research Journal, 50(3), 432-465.

Nadal, K. L. (2011). Racial and Ethnic Microaggressions Scale (REMS): Construction, reliability, and validity. Journal of Counseling Psychology, 58, 470-480.

Nadal, K. L., Wong, Y., Griffin, K. E., Davidoff, K., \& Sriken, J. (2014). The adverse impact of racial microaggressions on college students' self-esteem. Journal of College Student Development, 55(5), 461-474.

Nagda, B. A. (2006). Breaking barriers, crossing borders, building bridges: Communication processes in intergroup dialogues. Journal of Social Issues, 62(3), 553-576.

Norander, S., \& Galanes, G. (January 01, 2014). "Bridging the Gap": Difference, Dialogue, and Community Organizing. Journal of Applied Communication Research, 42(4), 345-365.

Orbe, M. P., \& Allen, B. J. (2008). "Race matters" in the journal of applied communication research. Howard Journal of Communications, 19, 201-220.

Pettigrew, T. F. (1998). Intergroup contact theory. Annual Review of Psychology, 49, 65-85.

Rowe, M. (2008). Micro-affirmations \& Micro-inequities. Journal of the International Ombudsman Association. 1(1)

Simpson, J. L. (2008). The color-blind double bind: Whiteness and the (im)possibility of dialogue. Communication Theory, 18(1), 139-159.

Smith, W. A., Mustaffa, J. B., Jones, C. M., Curry, T. J., \& Allen, W. R. (2016). 'You make me wanna holler and throw up both my hands!': Campus culture, Black misandric, microaggressions, and racial battle fatigue. International Journal of Qualitative Studies in 
Education, 29(9), 1189-1209.

Sue, D. W. (2010). Microaggressions and marginality: Manifestation, dynamics, and impact. Hoboken, NJ: John Wiley.

Sue, D. W. (2013). Race talk: The psychology of racial dialogues. American Psychologist, 68(8),

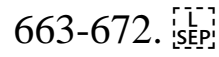

Sue, D. W., Capodilupo, C. M., Torino, G. C., Bucceri, J. M., Holder, A. M. B., Nadal, K. L., \& Esquilin, M. (2007). Racial microaggressions in everyday life: Implications for clinical practice. American Psychologist, 62(4), 271-286.

Sue, D. W., \& Constantine, M. G. (2007). Racial microaggressors as instigators of difficult dialogues on race: Implications for student affairs educators and students. College Student Affairs Journal, 26(2), 136-143.

Tajfel, H., \& Turner, J. C. (1979). An integrative theory of intergroup conflict. In W. G. Austin \& S. Worchel (Eds.), The Social Psychology of Intergroup Relations (pp. 33-47). Monterey, CA: Brookes-Cole.

Tracy, S. (2013). Qualitative research methods: Collective evidence, crafting analysis, communicating impact. Hoboken, NJ: Wiley-Blackwell. 